Anne Pellikka (PhD Candidate) is a university teacher in didactics of biology and geography in Faculty of Education, University of Oulu. Her research interests are in the fields of biology, geography and environmental education in the context of teacher education.

Sonja Lutovac, PhD is a postdoctoral researcher in the Faculty of Education, University of Oulu, Finland. Her research focuses on teacher identity development in the domains of mathematics and teacher education and explores the ways biographical experiences shape this process.

PhD Raimo Kaasila is a professor of teacher education and higher education at the University of Oulu in Finland. His main research area is professional development including teacher identity development, beliefs and emotions. He has applied narrative and rhetorical methods.

\title{
ANNE PELLIKKA
}

Faculty of Education, University of Oulu, Finland

Anne.Pellikka@oulu.fi

\section{SONJA LUTOVAC}

Faculty of Education, University of Oulu, Finland

sonja.lutovac@oulu.fi

\section{Relationships between pre-service primary teachers' beliefs, understandings, and planning of inquiry-based teaching in biology education}

\footnotetext{
Abstract

This study examines the relationships between pre-service primary teachers' (PSTs) beliefs, understandings, and planning of inquiry-based teaching (IBT) in biology education. In earlier studies, these relationships have been researched separately. Exploring them simultaneously allows a greater insight into the process of teacher change and professional development. Drawing on the narrative method, data included learning diaries, lesson plans, and interviews. The findings reveal the complex relationships between the three aspects of IBT. For example, PSTs embracing beliefs of IBT were sometimes accompanied by a significant understanding of IBT and other times by a weak understanding. Whereas, hesitant beliefs of IBT went together with significant understanding. We discuss these relationships in the light of their impact on teacher change and professional development and provide suggestions for teacher education.
} 


\section{INTRODUCTION}

The prominence of inquiry-based teaching (IBT) as student-centered approach and as contributor of nature of scientific knowledge has been acknowledged for many decades (National Research Council [NRC], 2012, 1996; Next Generation Science Standards, [NGSS], 2013; National Science Education Standards [NRC], 2000; Timmerman, Strickland \& Carstensen, 2008). The benefits of IBT in science teaching (Breslyn \& McGinnis, 2011; Minner, Levy, \& Century, 2010; Reiser, Tabak, Sandoval, Smith, Steinmuller \& Leone, 2001) include that it enhances student learning as well as the desired knowledge of scientific content and scientific practices (Alfieri, 2011; Furtak, Seidel, Iverson \& Briggs, 2012; Marshall, Smart \& Alston, 2017; NGSS, 2013; NRC, 2012). This means that students combine scientific practices such as formulating research questions, planning and carrying out investigations, analyzing and interpreting data, and constructing explanations and evaluate and communicate the findings (Furtak et al., 2012; NGSS, 2013; Zion, Cohen, \& Amir, 2007). IBT is also regarded for its benefits of efficiency in focusing on students' interests, and stimulating active learning and student participation in science education (Fitzgerald, Danaia \& McKinnon, 2019; Lehesvuori, Ratinen, Kulhomäki, Lappia \& Viiri, 2011).

However, there has been a debate, whether IBT truly increases the students achievements and whether it is as effective way of science teaching as it has been claimed to be (Jerrim, Oliver Sims, 2020; Kirschner, Sweller, \& Clark, 2006; Zhang, 2016). For example, it has been argued that the requirements of inquiry can exceed cababilities of young students (Kirschner et al., 2006) and that inquiry is not effective in enhancing student achievements if compared to teacher-led instruction (Jerrim et al., 2020). This debate also reflects the emphasis on two dimensions of inquiry: the cognitive processess and type of activities pupils engage in, and the degree of guidance provided by teachers (Furtak et al., 2012). In this study, we focus on the latter one, i.e. the level of inquiry in respect to how much the teacher provides instruction to students during inquiry-based teaching. The levels of inquiry presented in research literature include structured, guided and open inquiry (Banchi \& Bell, 2008; Fitzgerald et al., 2019), which form a continuum of the instruction provided by the teacher (Furtak et al., 2012).

In this study, preservice primary teachers (PSTs) are acquainted with inquiry-based learning as students and are simultaneously taught to use IBT as teachers, in their instruction. Our study examines IBT in biology education, since the PSTs in this study were introduced to IBT in the context of primary biology education. Furthermore, we follow previous literature which suggests that science teachers might approach inquiry differently e.g. in biology education than in other science subjects (Breslyn \& McGinnis, 2012; Schwartz \& Lederman, 2008). In our practices as teacher educators, we observed that PSTs have a variety of beliefs about IBT (see also, Weld \& Funk, 2005). Beliefs are individual's mental construction that have foundation in personal experiences and memories (Pajares, 1992). Whereas, Bandura (1997) maintains that beliefs predict the decisions that people make. Moreover, PSTs' beliefs about teaching are influenced by their memories of teaching and learning from their time at school (Carrier, Whitehead, Walkowiak, Luginbuhl \& Thomson, 2017; Lutovac \& Kaasila 2014, 2018; Pellikka, Lutovac \& Kaasila, 2018). Arguably, PSTs' subjective beliefs are particularly important if teacher educators want to encourage and, to a certain extent, ensure that PSTs incorporate IBT into their teaching.

Similarly, research has demonstrated that PSTs have different understandings of IBT (Lee \& Shea, 2016; Llewellyn, 2013; Seung, Park \& Jung, 2014). We differentiate understandings as more cognitive components and aforementioned beliefs as more affective components in PSTs' reflections of teaching (Clarke \& Hollingsworth, 2002; Pajares, 1992). Lastly, research has also brought forth that PSTs encounter challenges when choosing between the levels of inquiry when planning with the method (Maaß \& Artigue, 2013; Zion, Cohen \& Amir, 2007). Here, we also follow Capps and Crawford (2013) who maintain that to characterize teachers' refelection and thinking of their own teaching it is necessary to take multiple descriptors into account.

Thus, we examine the relationships between preservice primary teachers' (PSTs) beliefs, understandings, and planning of of inquiry-based teaching (IBT) in biology education. We were not able to find 
any studies addressing the relationships between these themes. Even though there are studies addressing the beliefs of IBT in relation to teacher change (Tam, 2015) and in relation to professional development (Lederman \& Lederman, 2012), these studies do not show the relationship between the three aspects of IBT. For teacher educators, it is particularly important to recognize the complexities in this relationship to support PSTs' learning of IBT. Therefore, the study is guided by the following research question: What are the variations in relationships between pre-service primary teachers' beliefs, understandings and planning of IBT?

\section{THEORETICAL FRAMEWORK}

\section{Understanding inquiry-based teaching}

Recently, there has been a shift from considering IBT as the prominent way of science teaching to consider IBT as process of engaging students to science and as a process of students participating in scientific practices (Bevins \& Price, 2016; Furtak, 2012; NGSS, 2013). In this respect, IBT should enhance both, the methodological understanding of doing science as well as understanding the scientific content knowledge. As a method, IBT should enhance applying scientific practices, like observing organisms and their relations, posing questions, designing and carrying out investigations, proposing explanations, collecting and analyzing data, presenting the results, and drawing conclusions (Marshall et al., 2017; NRC, 2012; Pedaste et al., 2015). And, as for content knowledge understanding, IBT should include students engaging their content knowledge with their scientific skills to develop their scientific way of thinking, scientific literacy, and understanding of the nature of science (Capps \& Crawford, 2013; Zion et al., 2007). Engaging students with the scientific practices and content knowledge also incorporates teaching how scientist use inquiry methods (Cairns \& Areepattamannil, 2017). In this study, we expected the PSTs' to understand that IBT includes the aforementioned scientific practises and that when those practices are combined with scientific content knowledge, they enhance the students' scientific way of thinking, scientific literacy, and understanding of the nature of science. Also, we agree with Lee and Shea (2016) who claim that for understanding IBT, the PSTs need to realize that the teacher is the one who encourages students to come up with their own questions and that the nature of these questions is exploratory or investigative.

Furthermore, the levels IBT form a continuum of how teacher- or student-led the IBT process is. In the continuum's teacher-led end is structured inquiry, where the question and procedure of finding an answer to the question are both provided by the teacher; further, in guided inquiry the teacher provides only the question giving students more responsibility of the carrying out the phases required to answer to the question; and lastly in open inquiry, which is at the student-led end of the continuum, the students create their own questions, design and carry out research and communicate their results indenpendently while teacher is seen as the facilitator of learning (Banchi \& Bell, 2008; Fitzgerald et al., 2019; Furtak et al., 2012; NRC, 2012). We decided to leave out the confirmatory inquiry from our study, since it provides the question, procedure and the answer for students and since it is used only to support the previously learned matter, leaving no space for student-led discovery (Banchi \& Bell, 2008). For this study then, it was relevant that PSTs' understood that they, as teachers, can differentiate between the level of instruction and thus, between the teacher- and student-led continuum of IBT (Banchi \& Bell, 2008; Furtak et al., 2012). Here, we want to emphasize, that since the PSTs in our study will teach primary school pupils, applying all principles of IBT was not expected.

Teacher educators, arguably, also need to be aware of the kind of misunderstandings of IBT their PSTs have. The most common misunderstandings include assuming that IBT is simply hands-on activity (Fitzgerald et al., 2019; Reiser et al., 2001). According to Llewellyn (2013), PSTs thought that IBT involves simply asking questions, whereas pre-service secondary science teachers thought that IBT is conducting certain routine procedures (Lee \& Shea, 2016). In biology teaching, teachers might assume that there is a dichotomy between method and content (Reiser et al., 2001) which in turn, might lead to disregard the creativity aspect in IBT (Maaß \& Artigue, 2013). Furthermore, according to Reiser et al. (2001) limited understanding of IBT can be translated into an inductive teaching style that focuses on mastering the content. 


\section{Pre-service primary teachers' beliefs about inquiry-based teaching}

Teachers' beliefs initiate from their prior personal experiences and from experience with schooling and instruction (Carrier et al., 2017; Miller \& Shifflet, 2016; Pellikka et al., 2018). The beliefs are understandings, assumptions or images that are felt to be true by an individual (Richardson, 1996), but are not necessary based on truth or knowledge (Nespor, 1987; Richardson, 1996). However, they often guide decisions and behavior of an individual. Kagan (1992) describes teacher belief as particularly provoking personal knowledge about teacher's implicit presumption of students, learning, and the subject matter to be taught. Thus, teachers' beliefs influence their acquisition and interpretation of knowledge and consequently they serve as cognitive filters through which decisions of teaching practices are perceived, implemented and reformed (Marcelo, 2009; Pajares, 1992). Although beliefs can be cognitive, the affective domain can also be emphasized in them (Pajares, 1992). Moreover, change in beliefs is considered challenging, and even if teachers change their beliefs, they do not necessarily change their practices (Pajares, 1992; Tam, 2015). Studies on changes in teachers' beliefs and practices suggests that change in teacher beliefs is followed by change in practice (Pajares, 1992; Tam, 2015). However, others suggest, that change in practice comes before the change in beliefs (Guskey, 1986, 2002; Devlin, 2006). Here, Korthagen (2017) reminds that besides cognitive dimension also affective and motivational dimensions should be considered as part of teachers' professional development.

Various courses in teacher education programs have been shown to assist PSTs' in developing and changing their beliefs of IBT in biology education. For example, Weld and Funk (2005) found out that modeling IBT strategies for PSTs during a biology course shifted their beliefs to perceive their roles as facilitators who ask good questions, make constant informal assessments, and convey an excitement for learning science. Whereas, the findings of Mashfufah, Nurkamto, Sajidan and Wiranto (2020) indicate that pre-service biology teachers' engagement, as well as understanding of inquiry is stronger at the beginning of inquiry cycle than at the end of it (see also Lehesvuori et al., 2011). Furthermore, the planning of IBT in biology education, requires teachers to shift their beliefs regarding the disciplinary content knowledge and shift their teaching approaches (Breslyn \& McGinnis, 2011). However, Seung et al. (2014) remind, that even though PSTs understand IBT, they do not directly plan their teaching with IBT.

\section{METHODS}

\section{Study context and data collection}

The study was conducted within the Environmental Studies (ES) course, which was the first science method course for the PSTs and included the contents and practices of biology, geography and health education. PSTs enrolled to the course during the first year of their studies and as one part of the course requirements PSTs participated in inquiry both as a learner and a teacher of biology. This meant that at first, the PSTs as learners were asked to conduct open inquiry in small groups since according to Putnam and Borko (2000), one way of ensuring teachers to incorporate method they are expected to use at school is having them experience the method by themselves. Secondly, the PSTs were asked to create inquiry-based lesson plan individually which engaged them to participate inquiry as teachers. Despite the fact that PSTs in our study were involved and trained in IBT, we acknowledge that one course may not be sufficient to achieve a full understanding of IBT.

The data collection procedure is described in the Figure 1. We examined pre-service primary teachers $(n=41)$ who enrolled to the ES-course. From the 41 PST, who gave their answers to Questionnaire 1 (Q1) we chose for further interviews (Int1, Int2) 11 PSTs who had the most positive, negative and neutral memories about biology and geography teaching and learning from their time at school, because we used this categorization in the wider study to choose the participants (see, Pellikka et al., 2018, 2020). The questions of the questionnaires (Q1, Q2) and interviews (Int1, Int2) can be found in Appendix 1. We also asked the participants of this study $(n=11)$ to keep a learning diary (LD), from which the content with IBT was used in this study. For the purposes of this study we asked the PSTs to create 
yet another biology lesson plan (LP) from the topic of Forest plants. This request was set in Q2 after the course and PSTs were allowed to choose the approach of their lesson plan freely. This meant that not all PSTs in this study chose to plan their LPs with IBT in Q2.

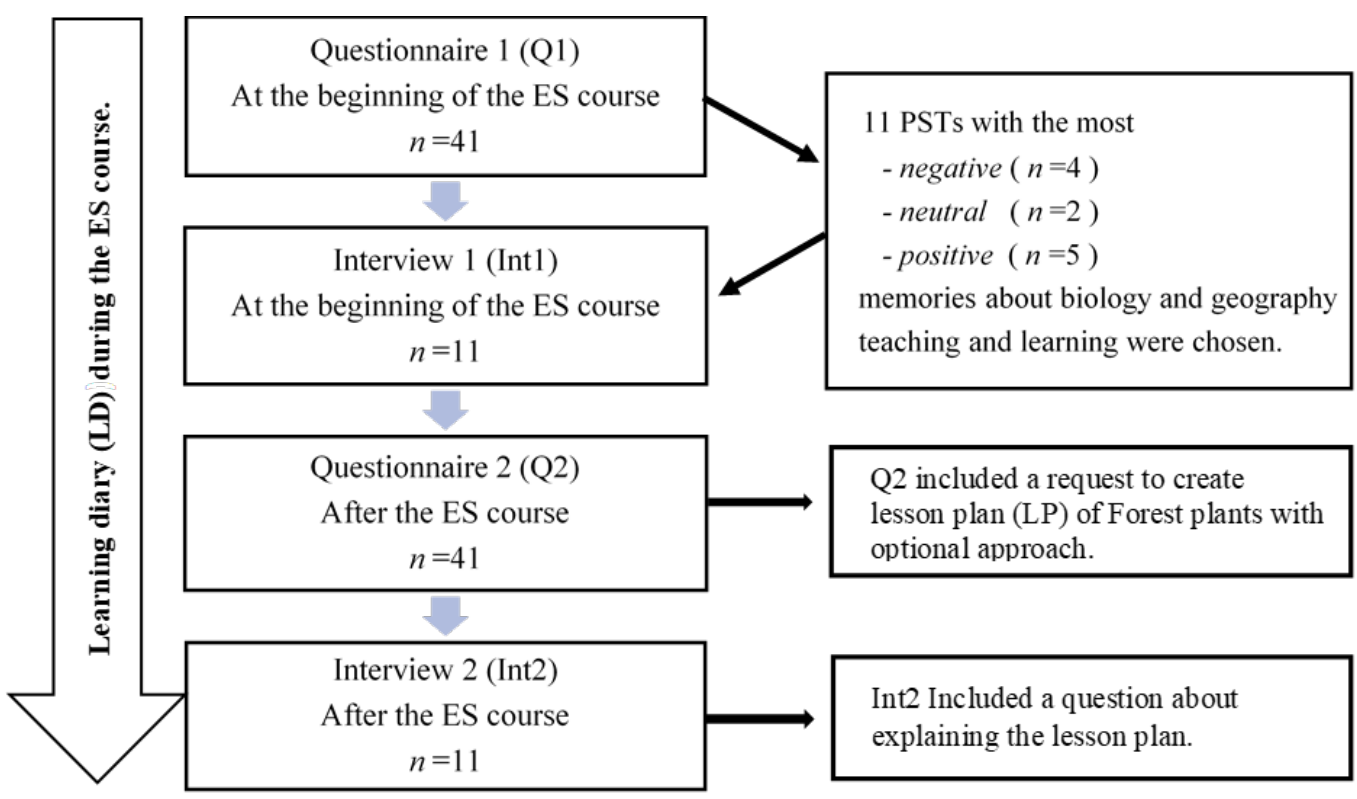

Figure 1. Data collection procedure during the science method course (10 weeks).

\section{Data Analysis}

The foundation of our narrative case study is in Polkinghorne's (1995) narrative analysis, which results in an emplotted narrative, a story that unites the relevant elements and reveals the meaning of the data (Lutovac \& Kaasila, 2014, 2018). Emplotment is not just a chronological listing of events; rather it aims at configuring a reflective explanation for an individual's decisions and experiences (Polkinghorne, 1995). Figure 2. describes data analysis procedure. First, we applied holistic-content reading which included the multiple cyclic readings of the entire data set (Int1, Q2, Int2, LD) (Lieblich, Tuval-Mashiach \& Zilber, 1998). Second, we looked into PSTs' LPs (Q2) to determine which level of IBT they had chosen, if any in their LPs. Therefore, when analysing the LPs, we characterized them as inquiry-based if they presented some of the levels of IBT, i.e. the structured, guided or open and thus presented either the teacher-led or the student-led inquiry (e.g. Banchi \& Bell, 2008; Furtak et al., 2012; Krystyniak \& Heikkinen, 2007). Finally, to compose the emplotted narratives presented in this study, we chose three cases, whose relationships between beliefs, understanding and planning of IBT were the most distinct and diverse. 


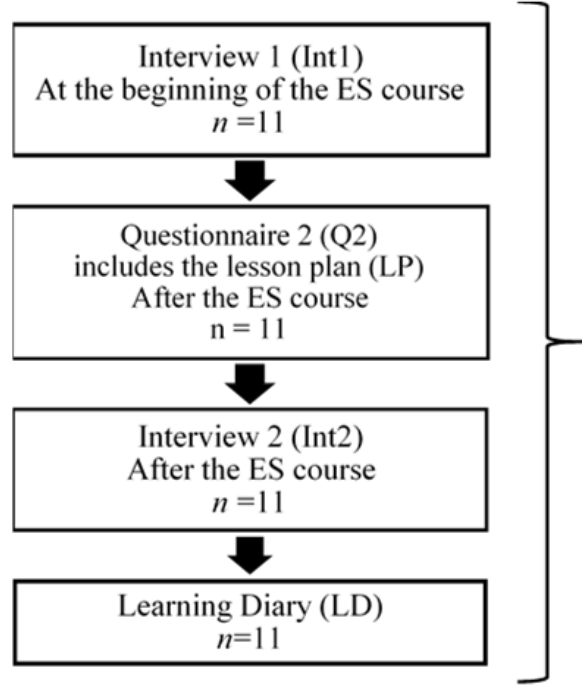

1. Holistic-content reading for the entire data set

\section{r}

2. Extracting all content related to IBT for each participant

\section{Rereading the extrcated data to reveal the beliefs, understandings, and planning of IBT}

\section{V}

4. Choosing the three cases that best portrayed the differences in relationships between beliefs, understandings, and planning of IBT

5. Writing the emplotted narratives of three cases

Figure 2. The data and the data analysis procedure (1.-5.) used in this study.

\section{RESULTS}

In the results we present first the relationships between beliefs, understandings and planning of IBT for all participants $(n=11)$ in Table 1 . We also present each PST's memories of biology and geography studies from their time at school at the beginning of course to either positive, negative, or neutral (Table 1.). The findings are based on 11 PSTs' interviews, LDs, and LPs. Following, we present three PSTs' narratives about IBT revealing the differences between the relationships of the three aspects. At the beginning of each narrative, we present a brief overview of the particular PST's beliefs, understandings and planning of IBT in their LPs.

In the Table 1. we first labeled PSTs' beliefs of IBT in terms of three categories: embracing, hesitant, and rejecting. A PST with embracing beliefs approves IBT and is willing to plan teaching with IBT, but a PST with hesitant beliefs is uncertain of planning with IBT and his or her own competence in planning of it. Finally, PSTs with rejecting beliefs disapproves IBT and rejects planning of it. Secondly, when we analyzed PSTs' understandings, we explored their understanding of IBT with its research-based definition, and observed that none of the PSTs fully understood the IBT cycle by the end of the course (Minner et al., 2010; NGSS, 2013; Pedaste et al., 2015). This is understandable because they are at the beginning of their teacher education studies and had no previous experience with IBT. However, even though none of the PSTs fully understood the cycle of IBT, we chose to categorize PSTs' understandings of IBT as significant, partial, and weak since they portrayed the differences between understandings the most distinct ways. A significant understanding means that the PST understood IBT almost fully, but his or her lack of experiences of IBT counters the full understanding. We came to this characterization via expressions such as: '...what can be more effective when it comes to learning than a child searching and producing knowledge by oneself' and 'It is essential that students conduct the question by themselves and then find an answer to it'. With partial understanding, the PST understood just some parts of IBT and used e.g. the following expressions: I feel that you can teach skills with IBT but not content knowledge.' Whereas with a weak understanding, the PST had great misconceptions or had misunderstood IBT and used expressions like: 'Inquiry is important merely as of the experience. Like when we played with microscopes I felt like little girl again, like please can I have a look also! To get that kind of experince is rare at this age.' 
Table 1. Beliefs, understandings, and planning of IBT at the end of ES course.

\begin{tabular}{|l|l|l|l|}
\hline $\begin{array}{l}\text { Student } \\
\text { (Memories: } \\
\text { positive, } \\
\text { negative, neutral) }\end{array}$ & $\begin{array}{l}\text { Beliefs } \\
\text { Embracing, hesitant, } \\
\text { rejecting }\end{array}$ & $\begin{array}{l}\text { Understanding } \\
\text { Significant, partial, } \\
\text { misunderstanding }\end{array}$ & $\begin{array}{l}\text { Planning of IBT in LP } \\
\text { Structured, } \\
\text { guided, open, } \\
\text { No IBT }\end{array}$ \\
\hline Kristiina (pos.) & Embracing & Significant & Open \\
\hline Sara (pos.) & Hesitant & Partial & Guided \\
\hline Kristian (pos.) & Embracing & Weak & Structured \\
\hline Kaarina (pos.) & Hesitant & Significant & Structured \\
\hline Nina (neg.) & Hesitant & Partial & No IBT \\
\hline Anita (neg.) & Embracing & Significant & Open \\
\hline Elli (neg.) & Embracing & Weak & No IBT \\
\hline Emma (neg.) & Embracing & Partial & Structured \\
\hline Stefan (neut.) & Rejecting & Weak & No IBT \\
\hline Tomas (neut.) & Rejecting & Partial & No IBT \\
\hline Mikael (neut.) & Hesitant & Partial & No IBT \\
\hline
\end{tabular}

Thirdly, we explored PSTs' planning of IBT by analyzing their lesson plans, and labeled them into four categories: structured, guided, open or no IBT level (No IBT) by how they presented the teacher- and student-led continuum. A stuctured LP used expressions like: 'The lesson would start with IBT question posed by a teacher: How do plants reproduce...? And then I would tell about the importance of plants as organism.' Whereas, the guided LP had expressions like: 'Teacher would ask students that is there anything in the forest that does not belong there. And then students could observe that is there such things.' In LP with open IBT there were expressions like: 'The students would draw those forest plants what they have seen earlier. Then we could observe the drawings together and find similar species. Then they could start thinking of the questions that comes up to their minds.' Lastly, the LPs that did not have any of the levels of IBT included expressions like: 'Teacher would define $a$ list of plants and students could choose one plant out of the list. After this we would go to forest and every student could try find that plant.'

\section{Pre-service primary teachers' narratives about inquiry-based teaching}

In this section, we zoom in on three participants' cases that represent the most distinct differences in the relationships between the participant's beliefs, understandings, and planning of IBT: Anita, Kaarina and Tomas. None of these participants had previous experience with IBT from their time at school and they had very few recollections of IBT from their first year in primary teacher education.

\section{Anita}

Anita's beliefs about IBT changed toward embracing during the ES-course. She also develops a significant understanding of IBT, since she underlines significance of the students' interest and student-led constructing knowledge in it. She finds IBT suitable and chooses open inquiry for her LP. At the beginning of the course, Anita doubted the students' ability to carry out such a difficult task as inquiry. She describes the process from the perspective of primary school students (Int1):

"It can be difficult for some students and... cause anxiety because the student is responsible [for learning]. When you are suddenly presented with a theme, and there are no question marks in it, you don't know where to answer to. Which can be difficult because you would need more developed thinking and brainwork." 
She continues in her LD:

"I think that especially IBT requires a huge amount of know-how from students. They must be able to think about the given topic or theme as an extensive entity in which you should find a small part and a question what to study."

According to her, comprehending content entities, and formulating questions are too challenging for primary school students. Explaining the challenges from student point of view reveals her understanding of the difficulties of IBT. However, she proposes how to facilitate the process of IBT (LD): 'Children should be practiced to IBT from the beginning so it would become routine and creating research questions would not be so difficult process.' She returns to the difficulty of formulating the research question and suggests how she could support students. This reveals her recognition of the difficulties in IBT, and shows that she has significant understanding of IBT.

However, during the course, Anita's beliefs toward IBT changed (LD):

"I was surprised how much I learned from inquiry-based group work, even though there were problems. In all, I feel that I got a lot of reusable material to my work as a teacher, also from other groups' presentations. ...I feel that I got a lot from inquiry-based small group working. Now it's easier to guide children in inquiry, since I have done it by myself."

Although Anita struggled with IBT at first, she develops embracing beliefs towards IBT. She learned from others during IBT and, therefore, wants to plan it in her teaching. She also values experiencing IBT because it enables her to better guide students in the method. Additionally, she reveals the most substantial facilitator for the change in her beliefs regarding IBT (Int2):

"I have seen it now. And I think it's [IBT] like an easy road to what I see as important in teaching, which is that students can choose themselves what to do. ... what can be more effective when it comes to learning than [a] child searching and producing knowledge by oneself and getting learning experiences in a different way."

For her, student interest and effective as well as different, less traditional way of learning in IBT are significant. Although her belief about IBT as a method where students can choose what to do is still quite undeveloped and naïve, the belief still brings forth that it is the student-led constructing of knowledge which changed her beliefs and aroused her to embrace open IBT. This is also presented in her LP at the end of the ES-course (Q2, Int2):

"I thought a lesson in forest, where children are asked about their feelings towards it and what does that feeling mean to them? This conversation is the most important part of the lesson. Students could go into pairs and choose interesting plants from the forest and photograph them, not familiar, necessarily. Then they could choose one and they could observe it... and search information of it. ...it would be hands-on doing. The meaning is not that everyone searches the same species [predetermined by the teacher] but everyone could search what interests oneself. Then they could give a small presentation of the plant and tell all the facts and why it was interesting."

Anita's LP shows how the construction of knowledge is student-led since student interest is used as basis for choosing the plant. This indicates that the level of IBT in the LP is open. The students' independent observing, carrying out investigation (search information) and giving presentation are explicated as well, which in turn indicates of the use of scientific practices. However, in IBT the presenting the results phase should also preceed or include evaluating of the new knowledge and drawing conclusions which is missing here. This implies that Anita has not fully understood what the meaning of the presentation of the results phase is. 


\section{Kaarina}

Kaarina's beliefs about IBT remain hesitant throughout the ES-course, even though she develops significant understanding of it. Because of her hesitant beliefs, she chooses the level of structured IBT in her LP. At the beginning of the ES course Kaarina is confused by the discrepancy between her preconceptions about IBT and the definition of inquiry in the ES course (Int1). 'Ever since this course started, I have become totally unaware that what inquiry-based teaching is ...I have thought that it is practical and hands-on doing like [example of preparation of specimens].' This discrepancy overshadows her beliefs about IBT and leaves her struggling to understand it (Int1):

"I think I overthink it. It's a difficult concept. Goes beyond my imagination. ... What is the question in it? ...I think that we haven't got it in our upper secondary school biology studies. ...Somehow it feels so hard to imagine that, how the students could define any questions."

She acknowledges how puzzled she is with IBT, she even recalls her upper secondary school memories to better understand the method. This leads her to doubt the capabilities of children also. In her LD, she reflects on the changes in her understanding during the ES course (LD):

"I realized that it has been unclear to me that what inquiry actually is. I have thought that it is hands-on doing and [the] opposite of teacher-led teaching. ...But any hands-on doing is not inquiry. If students are examining [a specimen] and finding out what is inside of it, [this] is not necessarily inquiry. It is essential that students conduct the question by themselves and then find an answer to it."

This reveals that Kaarina has developed significant understanding of the essential role of students formulating the research question in open inquiry.

At the end of the course, Kaarina remains confused about applying IBT (Int2):

"Maybe I just think too complicatedly since with smaller students it can be as easy as was the [subject] example during the [ES] course. I can't simplify it in my head; I mean how simple IBT could be. I think I can apply it if I get [a] little help from more experienced teachers and if I have enough time to plan it."

She remains with the same hesitant beliefs towards IBT, as was at the beginning of the course. She can't visualize how to deliver IBT to students and desires a model of IBT coming from competent teacher. Her LP shows that she prefers a more teacher-led teaching (Q2, Int2):

"We would go to the forest or park where the plants would be concretely in front of us. Then we would draw a plant to paper and find out more information from the botany guide or Internet so that we could have more scientific facts about the plant. Then we could give a presentation from the plants to others so that we would practice oral presentation and group work."

Kaarina uses the pronoun "we", which makes it difficult to know what is it that students are doing. She does not refer to student-led interest or activity but rather teacher-led proceeding of the lesson, thus her LP is on stuctured level of IBT. Also drawing the plant and finding information seems to be teacher-led observation and carrying out investigation, indicating again of structured level of IBT. Even though, the presentation of findings could be considered as part of presenting the results in IBT, it does not show the evaluation findings nor drawing conclusions, as did not Anita's LP either. In Kaarina's LP the presentation is rather planned simply to practice oral presentation and group work skills. 


\section{Tomas}

Tomas has rejecting beliefs about IBT throughout the ES-course. He understands and values the benefits of guided inquiry. However, he does not choose any of levels of IBT in his LP. At the beginning of the ES course Tomas shares his thoughts about the teacher's role in IBT (Int1):

"Maybe as a teacher, I would like to frame those research questions more [in IBT], in a way that I would give them exercises and questions, and I would lead them to the direction I want them to go. In my opinion, the teacher's role in guiding should be bigger."

Tomas refers repeatedly to the teacher's role, which shows that he accepts structured and guided inquiry. However, this leaves him without an understanding of the value of student-led constructing of knowledge in open IBT.

In his LD during the course, Tomas also acknowledges how difficult IBT is for primary school students (LD):

"I think it is really demanding and requires the higher-order cognitive skills, like analysis. I doubt that primary school students have the basic skills required by it. ...it doesn't fit to primary school settings, where you learn things for the first time."

Tomas gives multiple reasons for why he is confident that IBT is beyond the capabilities of primary school children. This reveals Tomas's rejecting beliefs towards IBT.

In the interview after the course, Tomas's rejecting beliefs about IBT endure (Int2):

"It works well in theory, but in primary school one will throw the baby [out] with the bath water....It requires learning and meta-skills and responsibility, but if you want learning outcomes with IBT, it's not going to work in primary school. ...I feel that you can teach skills with IBT but not content knowledge."

Again, Tomas is questioning the effectiveness of IBT when it comes to learning content knowledge. He values only the methodological aspect of IBT and is left with only partial understanding of it.

As a future primary science teacher, Tomas maintains his teacher-led beliefs about IBT and finally consents to guided inquiry (Int2):

"In IBT, there is students' own curiosity, but there are still more downsides. As a teacher, I would like to offer them the questions from which they could choose the most interesting one. That would be the maximum I could yield in this sort of thing. I could implement it [IBT] if the problem is fitting."

Yet, his LP is reflecting again more teacher-led and content-oriented beliefs (Int2):

"[In a forest] we aim to define what is a plant and classify plants to larger groups like trees, grasses, mosses, etc. ...Then we could play plant spotting where the teacher would say a common part of the plant structure or name of the plant and students would try to find it. ...The main point would be being outside, classification ... and hands-on doing."

Tomas is also using the "we" pronoun along with telling what teacher would say and how students would act accordingly. He does not express any student-led activities either. This indicates the teacher-led teaching orientation in his LP and does not plan a lesson according to any of the three levels of IBT. 


\section{DISCUSSION}

Our study focused on describing the complex and intertwined relationships between PSTs' beliefs, understandings, and planning of IBT in biology education. For 11 PSTs, we examined the relationships between the mentioned aspects and provided detailed narratives of three PSTs with the most differing relationships (Table 1). Some examples of these relationships are embracing beliefs - significant understanding - planning open IBT; hesitant beliefs - significant understanding - planning structured IBT; and rejecting beliefs - partial understanding - no IBT planned. Examining the three aspects at the same time allowed more insight into the process of teacher change and professional development. The findings suggest that the relationships between beliefs, understanding and planning of IBT in lesson plans in biology teaching are inconsistent (cf. Zion et al., 2007). Even though, the three aspects have been earlier studied separately in biology and in general science education (e.g. Lederman \& Lederman, 2012; Weld \& Funk, 2005), bringing them together and observing them in terms of relationships, revealed how these relationships vary. This also allowed more insight into the process of teacher change, and, consequently, helped us see how we could better support our teacher students while they are learning to teach.

Furthermore, our findings revealed that those PSTs who hold embracing beliefs and have displayed significant understanding of IBT have also planning of IBT in their LPs. This is quite natural because when PSTs like the method and feel engaged, they tend to feel confident to apply it too (Mashfufah et al., 2020). Such a relationship increases the likelihood that PSTs would use the method in the long run. Also, this relationship included the first concerns of how students could perform inquiry and later experiences of effective and independent learning as a student (Breslyn \& McGinnis, 2011). This shift between the teacher and the student reveals the contribution on teacher change. The finding suggests that in teacher education it might be valuable to anticipate that fully aligned relationship between the aspects regarding IBT contributes significantly to teachers' professional development.

Moreover, the changes in PSTs' beliefs, understandings, and planning of IBT are not necessarily synchronous, and the relationship between them is also dynamic and open to change. Some beliefs may endure changes, regardless of the PSTs' understandings. In our study, this was the case with hesitant beliefs despite the PSTs' significant understanding of IBT. One reason for this relationship is that PSTs in the course began problematizing their current beliefs and practices that they had been exposed to in the past, especially when contrasted to their teacher-led biology classes at school. For such a dyssynchronous relationship, experiencing IBT during the course was clearly not enough to contribute to an efficient change in beliefs. One reason for such a slow change or no change at all is that PSTs' beliefs are, after all, greatly bound to their socio-historical past, including their school memories (Lutovac \& Kaasila, 2014, 2018; Carrier et al., 2017; Tam, 2015). Also, since the hesitant beliefs preserved the teacher-led orientation despite the significant understanding of IBT, the affective dimension in professional development was so significant that it countered the cognitive dimension (Korthagen, 2017). This finding reveals that the affective dimension can carry a great significance, indicating, that the balance between the affective and cognitive dimensions is essential to promote the professional development process. Thus, in teacher education it should be acknowledged that even the PSTs with significant understanding of IBT need encouragement in practicing of IBT.

Finally, the resistance to changes in beliefs is also evident in the relationship where rejecting beliefs were accompanied by partial understanding. Even though the participants in our study went through the process of learning about and experiencing the IBT process during the course and have at least partially understood the method, the beliefs did not change to become more embracing (cf. Devlin, 2006; Guskey, 1986, 2002). Here, the rejecting beliefs seem to stem from partial understanding and prevent the planning of IBT, indicating very unchangeable relationship between the three aspects of IBT. Some reasons for unchangeable relationship could be attributed to inability to see how content could be learned through IBT, the strong emphasis on teacher-led teaching, and a lack of acknowledgment of student-led constructing of knowledge. This reveals that the unchangeable relationship is rationalized, displaying that only the cognitive dimension of teacher change is allowed to be pursued and also, echoing of very inflexible process of professional development. Therefore, in teacher educa- 
tion it should be acknowledged that the relationships between PSTs' beliefs, understanding and planning of IBT may affect PSTs' professional development to appear stable and unchanging. However, this apparent stability, might become more dynamic again, if PSTs are offered different experiences and contexts to reconsider the relationships of different aspects related to IBT. Even PSTs who have made conscious decision to not plan of IBT (Maaß \& Artigue, 2013) should be encouraged to better alignment between the aspects through challenging them and providing safe opportunities to try the approach.

\section{CONCLUSIONS}

To conclude, our study is a small scale narrative research; therefore, we by no means want to generalize our findings. The findings do, however, shed new light on some well-discussed issues. In addition, we believe that teacher educators of science, and especially biology courses may find the patterns of relationships we described in this paper among their PSTs. Thus, we provide the following recommendations for primary biology teacher education.

Firstly, the finding about inconsistent relationships between PSTs' beliefs, understandings and planning of IBT in biology education displays the need that teacher education might benefit from identifying the relationships in respective biology education settings.

Secondly, our findings reveal the significant contribution of the relationships between PSTs' beliefs, understandings and planning of IBT for PSTs' professional development. For example, the aligned relationship has pinpointed that the understanding of the student-led construction of knowledge in IBT is essential for the dynamic process of teacher change. Moreover, dyssynchronous relationship further indicated the power of the affective dimension in teacher change. These findings suggest that endorsing the balance between affective and cognitive dimensions in professional development is a fundamental task in teacher education.

Lastly, our findings revealed that the seemingly unchangeable relationships between PSTs' beliefs, understandings and planning of IBT might indicate inflexibility in teacher change. This, in teacher education, should be addressed with offering PSTs' more possibilities to re-consider the relationships between their beliefs, understandings and planning of IBT and further, reconsider how the dynamics in the relationships affect to their professional development.

\section{REFERENCES}

Alfieri, L., Brooks, P. J., Aldrich, N. J., \& Tenenbaum, H. R. (2011). Does discovery-based instruction enhance learning?. Journal of educational psychology, 103(1). https://doi.org/10.1037/ aoo21017

Banchi, H., \& Bell, R. (2008). The many levels of inquiry. Science and children, 46(2), 26.

Bandura, A. (1997). The anatomy of stages of change. American journal of health promotion: AJHP, 12(1), 8-10.

Bevins, S., \& Price, G. (2016). Reconceptualising inquiry in science education. International Journal of Science Education, 38(1), 17-29. https://doi.org/10.1080/09500693.2015.1124300

Breslyn, W., \& McGinnis, J. R. (2012). A comparison of exemplary biology, chemistry, earth science, and physics teachers' conceptions and enactment of inquiry. Science Education, 96(1), 48-77. https://doi.org/10.1002/sce.20469

Carrier, S. J., Whitehead, A. N., Walkowiak, T. A., Luginbuhl, S. C., \& Thomson, M. M. (2017). The development of elementary teacher identities as teachers of science. International Journal of Science Education, 39(13), 1733-1754. https://doi.org/10.1080/09500693.2017.1351648

Capps, D. K., \& Crawford, B. A. (2013). Inquiry-based instruction and teaching about nature of science: Are they happening?. Journal of Science Teacher Education, 24(3), 497-526. https://doi. org/10.1007/s10972-012-9314-z 
Clarke, D., \& Hollingsworth, H. (2002). Elaborating a model of teacher professional growth. Teaching and teacher education, 18(8), 947-967. https://doi.org/10.1016/So742-051X(02)00053-7

Devlin, M. (2006). Challenging accepted wisdom about conceptions of teaching in academic development. Doctoral dissertation, University of Melbourne. http://hdl.handle.net/10536/DRO/ DU:30006685

Fitzgerald, M., Danaia, L., \& McKinnon, D. H. (2019). Barriers inhibiting inquiry-based science teaching and potential solutions: perceptions of positively inclined early adopters. Research in Science Education, 49(2), 543-566. https://doi.org/10.1007/s11165-017-9623-5

Furtak, E. M., Seidel, T., Iverson, H., \& Briggs, D. C. (2012). Experimental and quasi-experimental studies of inquiry-based science teaching: A meta-analysis. Review of educational research, 82(3), 300-329. https://doi.org/10.3102/0034654312457206

Guskey, T. R. (1986). Staff development and the process of teacher change. Educational researcher, 15(5), 5-12. https://doi.org/10.3102/0013189X015005005

Guskey, T. R. (2002). Professional development and teacher change. Teachers and teaching, 8(3), 381-391. https://doi.org/10.1080/135406002100000512

Jerrim, J., Oliver, M., \& Sims, S. (2020). The relationship between inquiry-based teaching and students' achievement. New evidence from a longitudinal PISA study in England. Learning and Instruction. https://doi.org/10.1016/j.learninstruc.2020.101310

Kaasila, R., \& Lauriala, A. (2010). Towards a collaborative, interactionist model of teacher change. Teaching and Teacher Education, 26(4), 854-862. https://doi.org/ 10.1016/j.tate.2009.10.023

Kagan, D. M. (1992). Implication of research on teacher belief. Educational psychologist, 27(1), 6590. https://doi.org/10.1207/s15326985ep2701_6

Kirschner, P. A., Sweller, J., \& Clark, R. E. (2006). Why minimal guidance during instruction does not work: An analysis of the failure of constructivist, discovery, problem-based, experiential, and inquiry-based teaching. Educational psychologist, 41(2), 75-86. https://doi.org/10.1207/ s15326985ep4102_1

Korthagen, F. (2017). Inconvenient truths about teacher learning: Towards professional development 3.o. Teachers and teaching, 23(4), 387-405. https://doi.org/10.1080/13540602.2016.121 1523

Krystyniak, R. A., \& Heikkinen, H. W. (2007). Analysis of verbal interactions during an extended, open-inquiry general chemistry laboratory investigation. Journal of Research in Science Teaching: The Official Journal of the National Association for Research in Science Teaching, 44(8), 1160-1186. https://doi.org/10.1002/tea.20218

Lederman, N. G., \& Lederman, J. S. (2012). Nature of scientific knowledge and scientific inquiry: Building instructional capacity through professional development. In B. J. Fraser, K. Tobin \& C. J. McRobbie (Eds). Second international handbook of science education (pp. 335-359). Springer, Dordrecht. https://doi.org/10.1080/1046560X.2019.1625572

Lee, C. K., \& Shea, M. (2016). An analysis of pre-service elementary teachers' understanding of inquiry-based science teaching. Science Education International, 27(2), 217-237.

Lehesvuori, S., Ratinen, I., Kulhomäki, O., Lappia, J., \& Viiri, J. (2011). Enriching primary student teachers' conceptions about science teaching: Towards dialogic inquiry-based teaching. NorDi$\mathrm{Na}$ : Nordic Studies in Science Education, 7(2), 140-159. https://doi.org/10.5617/nordina.235

Lieblich, A., Tuval-Mashiach, R., \& Zilber, T. (1998). Narrative research: Reading, analysis, and interpretation (Vol. 47). London: Sage. https://doi.org/10.4135/9781412985253

Llewellyn, D. (2013). Inquire within: Implementing Inquiry- and Argument-Based Science Standards in Grades 3-8. Thousand Oaks, CA: Corwin Press.

Lutovac, S., \& Kaasila, R. (2014). Pre-service teachers' future-oriented mathematical identity work. Educational Studies in Mathematics, 85(1), 129-142. https://doi.org/10.1007/s10649-0139500-8.

Lutovac, S., \& Kaasila, R. (2018). An elementary teacher's narrative identity work at two points in time two decades apart. Educational Studies in Mathematics, 98(3), 253-267. https://doi.org/ 10.1007/s10649-018-9816-5 
Maaß, K., \& Artigue, M. (2013). Implementation of inquiry-based learning in day-to-day teaching: a synthesis. ZDM, 45(6), 779-795. https://doi.org/10.1007/s11858-013-0528-o

Marcelo, C. (2009). Professional Development of Teachers: past and future. Sísifo. Educational Sciences Journal, 8, 5-20.

Marshall, J. C., Smart, J. B., \& Alston, D. M. (2017). Inquiry-based instruction: A possible solution to improving student learning of both science concepts and scientific practices. International journal of science and mathematics education, 15(5), 777-796. https://doi.org/10.1007/ s10763-016-9718-x

Mashfufah, A., Nurkamto, J., Sajidan, S. \& Wiranto, W. (2020). The Level of Inquiry among Preservice Biology Teachers. Universal Journal of Educational Research, 8(3), 7-12. https://doi. org/10.13189/ujer.2020.081702

Miller, K., \& Shifflet, R. (2016). How memories of school inform preservice teachers' feared and desired selves as teachers. Teaching and Teacher Education, 53, 20-29. https://doi.org/10.1016/j. tate.2015.10.002

National Research Council (2012). A framework for K-12 science education: Practices, crosscutting concepts, and core ideas. National Academies Press, Washington, DC. https://doi. org/10.17226/13165

National Research Council. (2000). Inquiry and the national science education standards: A guide for teaching and learning. National Academies Press, Washington, DC. https://doi. org/10.17226/9596

Nespor, J. (1987). The role of beliefs in the practice of teaching. Journal of curriculum studies, 19(4), 317-328. https://doi.org/10.1080/0022027870190403

NGSS Lead States. (2013). Next Generation Science Standards: For states, by states (vol. 1, The Standards). Washington, DC: The National Academies Press. Retrieved December 6, 2020 from http://www.nextgenscience.org/next-generation-science-standards

Pajares, M. (1992). Teachers' beliefs and educational research: Cleaning up a messy construct. Review of Educational Research, 62(3), 307-332. https://doi.org/10.3102/00346543062003307

Pedaste, M., Mäeots, M., Siiman, L. A., de Jong, T., van Riesen, S. A., Kamp, E. T., \& Tsourlidaki, E. (2015). Phases of inquiry-based learning: Definitions and the inquiry cycle. Educational Research Review, 14, 47-61. https://doi.org/10.1016/j.edurev.2015.02.003

Pellikka, A., Lutovac, S., \& Kaasila, R. (2018). The nature of the relation between pre-service teachers' views of an ideal teacher and their positive memories of biology and geography teachers. NorDiNa: Nordic Studies in Science Education, 14(1), 82-94. https://doi.org/10.5617/nordina. 4368

Pellikka, A., Lutovac, S., \& Kaasila, R. (2020). The change in pre-service primary teachers' possible selves in relation to science teaching. European Journal of Teacher Education, 1-17. https:// doi.org/10.1080/02619768.2020.1803270

Polkinghorne, D. E. (1995). Narrative configuration in qualitative analysis. International Journal of Qualitative Studies in Education, 8(1), 5-23. https://doi.org/10.1080/0951839950080103

Putnam, R. T., \& Borko, H. (2000). What do new views of knowledge and thinking have to say about research on teachers' learning? Educational Researcher, 29(1), 4-15. https://doi. org/10.3102/0013189X029001004

Reiser, B. J., Tabak, I., Sandoval, W. A., Smith, B. K., Steinmuller, F., \& Leone, A. J. (2001). BGuILE: Strategic and conceptual scaffolds for scientific inquiry in biology classrooms. Cognition and instruction: Twenty-five years of progress, 263-305.

Richardson, V. (1996). The role of attitudes and beliefs in learning to teach. In J. Sikula, T. J. Buttery, \& E. Guyton (Eds.), Handbook of Research on Teacher Education, 2. ed. (pp. 102-119). Macmillan, New York.

Schwartz, R., \& Lederman, N. (2008). What scientists say: Scientists' views of nature of science and relation toscience context. International Journal of Science Education, 30(6), 727- 771. https://doi.org/10.1080/09500690701225801 
Seung, E., Park, S., \& Jung, J. (2014). Exploring preservice elementary teachers' understanding of the essential features of inquiry-based science teaching using evidence-based reflection. $R e-$ search in Science Education, 44(4), 507-529. https://doi.org/10.1007/s11165-013-9390-x

Tam, A. C. F. (2015). The role of a professional learning community in teacher change: A perspective from beliefs and practices. Teachers and Teaching, 21(1), 22-43. https://doi.org/10.1080/1354 0602.2014.928122

Timmerman, B. E., Strickland, D. C., \& Carstensen, S. M. (2008). Curricular reform and inquiry teaching in biology: where are our efforts most fruitfully invested?. American Zoologist, 48(2), 226-240. https://doi.org/10.1093/icb/icno64

Weld, J., \& Funk, L. (2005). "I'm not the science type": Effect of an inquiry biology content course on preservice elementary teachers' intentions about teaching science. Journal of Science Teacher Education, 16(3), 189-204. https://doi.org/10.1007/s10972-005-4860-2

Zion, M., Cohen, S., \& Amir, R. (2007). The spectrum of dynamic inquiry teaching practices. Research in Science Education, 37(4), 423-447. https://doi.org/10.1007/s11165-006-9034-5

Zhang, L. (2016). Is inquiry-based science teaching worth the effort?. Science \& Education, 25(7-8), 897-915. https://doi.org/10.1007/s11191-016-9856-0 


\section{APPENDIX 1}

\section{Questionnaire 1}

1. What kind of memories do you have from biology and geography lessons from your time at school?

2. How would you describe yourself as a learner of biology and geography?

3 . How would you describe yourself as a teacher of biology and geography?

4. What kind of teacher of biology and geography you would like to be?

\section{Interview 1}

\section{Memories}

a) Tell what kind of experiences you have from learning and teaching biology and geography from your time at school?

b) Tell more about your biology and geography teachers.

c) What memory related to biology and geography teaching and learning from your time at school is the most significant for you as a future teacher?

2. As a teacher

a) Tell how would you describe yourself as a teacher of biology and geography?

b) What kind of teacher of these subjects you would not like to be?

c) Tell, what is the most important task of biology and geography teacher?

3. As a teacher in the future

a) Tell what kind of teacher of biology and geography you would like to be in the future?

b) What are the most important features of teacher that you mentioned?

\section{Questionnaire 2}

1. a) What was the most significant learning experience for you as a future teacher of environmental studies during the course?

b) What was challenging during the course?

2. How would you describe yourself as a teacher of biology and geography now?

3. Describe a lesson with the topic of "Forest plants" that you would like to implement.

\section{Interview 2}

1. Experiences from the course

a) Tell what the most significant experiences for you during the course were

b) How did your views about teaching and learning biology, geography or environmental studies changed during the course?

c) Tell what was challenging for you?

2. As a teacher

a) Tell how would you describe yourself as a teacher of biology and geography now?

b) Tell what kind of goals you would set for yourself now as a future teacher of these subjects?

3. Lesson plan

a) Tell more about the lesson with the topic of "Forest plants" that you described in Questionnaire 2.

b) What is the most important phase or element in the lesson and why? 